\title{
O ESCRITOR PROFISSIONAL
}

Tiago Velasco é doutorando em Literatura, Cultura e Contemporaneidade na PUC-RIO, bolsista da CAPES e escritor.

E-mail: velasco.tiago@gmail.com

\section{Introdução}

Escrevo para o meu pai e para a minha mãe (sou filho). Para a minha namorada (sou heterossexual). Para os meus irmãos. Para meus professores e professoras (sou doutorando em Letras). Para os meus amigos. Para meus alunos e alunas (sou professor de Comunicação Social). Para leitores presumidos (eu mesmo?). E todos eles (meus espelhos) escrevem comigo.

Sou escritor profissional. Estas linhas que vocês leem é um artigo para uma disciplina no doutorado. Olho para mim durante o processo de escrita desse texto. E me construo a cada palavra digitada, autorreflexivo. Nem tudo é o que parece nesse artigo, altero sinceridade e cinismo, por vezes inconscientemente. Não é à toa, tenho um objetivo. Ergo uma fachada pessoal. Estou fadado ao insucesso. Sei que vou falhar atravessado pelas contingências.

\section{Fachada pessoal}

1

Terminei o mestrado em Comunicação e Cultura em abril de 2010. Deveria ter defendido a dissertação em fevereiro. Não consegui. Pedi adiamento. Eu tinha direito, nunca tive bolsa. Atrasei a conclusão porque tive que trabalhar simultaneamente ao mestrado. Foi o que falei na secretaria da universidade. Talvez eu acreditasse nessa história. Eles não se importavam, nem com a minha história nem com a minha interpretação sofrida, um tanto canastrona, de uma autocomiseração deplorável.

- Solicita por escrito, pede pra sua orientadora assinar.

Ele nem olhou para o meu rosto, continuou voltado para a tela do computador, executando o trabalho a que se dedicava antes de eu chegar à recepção. Não viu minha cabeça baixa, muito menos meu olhar de quem clama por caridade. Apenas ouviu a minha voz para dentro e hesitante. Fui preparado para convencê-lo, apelando ao sentimento de compaixão ou até mesmo de culpa que deveriam existir ainda em algum lugar daquele ser embrutecido pela burocracia, em uma atuação com tal nível de dramaticidade que orgulharia o jovem Werther. Desnecessária. Bastava seguir os procedimentos.

Deixei a secretaria ansioso com os meses que ganhei para finalizar o trabalho. Dormir estava se tornando impossível naqueles dias.

2

Desenvolvi o meu personagem professor na primeira vez que dei aula. De lá para cá, aprimorei-o, dispensando o que considero não haver funcionado, amenizando certos traços e absorvendo outros, mas a essência dele permanece presente toda vez que entro em sala e encaro os alunos. É um personagem um pouco agressivo, irônico, engraçado, expansivo, atencioso, camarada, rigoroso. Uma forma de, em um primeiro 
momento, controlar o meu medo de me ver frente a frente com os alunos, transferindo para eles o receio. Tímido, assumi uma postura quase de enfrentamento como forma de me proteger. Aos poucos, confesso, comecei a me divertir com o personagem. Como em um show, o incorporo assim que adentro a sala de aula, desincorporando-o tão logo me retiro. E, então, volto a ser tímido, cumprimentando a todos com um fio de voz.

3

Um dia papai me chamou na sala. Queria ter uma conversa séria. Foi assim mesmo que ele se referiu ao papo, "conversa séria". Do conteúdo a seguir, não me recordo muito bem, não posso garantir se é a verdade dos fatos, mas certamente foi essa expressão que ele usou quando me chamou à sala: "conversa séria".

- E então, este ano todo te dei uma grana para você viabilizar uma mudança na sua vida. Mês que vem é o último que te darei o dinheiro. Nada mudou. O que você vai fazer da vida?

Eu já era mestre em Comunicação, já era professor universitário, já tinha dois livros publicados, mas papai queria mais para o filho, papai não estava contente, papai tinha ambições.

- Quando é que você vai arrumar um emprego sério, em uma empresa grande, estável, que tenha um plano de saúde...?

Ah, papai estava preocupado com a minha saúde.

- A faculdade que dou aula me dá plano de saúde, mas eu não aceito porque o plano aqui de casa é um plano empresa, você mesmo me disse que precisa de no mínimo quatro pessoas. Se eu sair do plano, vocês terão que trocar para um pior.

- É verdade. Mas o que eu quero saber é sobre os seus planos pro futuro. Quais são?

Papai estava fazendo a função de pai preocupado com o filho de 33 anos que não tinha dinheiro para se sustentar fora da casa dele. Falei que ia fazer o processo seletivo para o doutorado, mas que nada garantia que eu ia passar, o número de vagas era limitado e era uma competição. Expliquei que se passasse, ainda assim não teria dinheiro para me sustentar fora da casa dele, era algo demorado, um período de quatro anos para, só então, estar apto a fazer concursos para professor universitário. E que o salário de professor adjunto era...

- Tá, qual o plano B?

4

A essa altura você, leitor, já deve ter percebido que faço aqui um artigo memorialístico. Escritor profissional que sou, me aventuro por diferentes registros e formas narrativas. Este, como já revelei, é um artigo acadêmico e, assim, é de bom tom salpicá-lo com citações. Embasa o pensamento e mostra erudição.

Desse antigo verão que me alterou a vida restam ligeiros traços apenas. $\mathrm{E}$ nem deles posso afirmar que efetivamente me recorde. $O$ hábito me leva a criar um ambiente, imaginar fatos a que atribuo realidade. (Graciliano Ramos) 
Há alguns meses comecei a usar o Tinder, um aplicativo de celular para pessoas que querem encontrar parceiros para eventuais relacionamentos amorosos, efêmeros ou não. É simples e viciante. Basta ativar alguns filtros, critérios básicos para definir o perfil das pessoas que o aplicativo vai apresentar a você. Nada muito complexo: distância em relação a onde você está, o gênero da pessoa que você quer conhecer e a faixa de idade. Pronto, o jogo começa. Quem utiliza o Tinder quer praticidade: checa rapidamente as fotos, lê o texto de autodescrição de cada um e quantos amigos têm em comum. Todos escolhendo os melhores ângulos e atributos para expor na vitrine virtual. Em seguida, movimentos ágeis de dedos, como os de um esgrimista com seu florete, sobre a touchscreen do smartphone garantem a seleção ou não de um possível parceiro. Em algum outro lugar, uma outra pessoa está fazendo o mesmo. Quando ambos dão like mutuamente, ocorre o match e uma aba de bate-papo se abre.

$\mathrm{Na}$ época em que usava o Tinder, tive vários matches, mas só marquei de sair mesmo uma vez. Em geral, após o primeiro contato no aplicativo, preferia me transferir para o Facebook. E era lá que ocorria o desencantamento. O conflito de perfis entre o Facebook e o Tinder. Enquanto no aplicativo amoroso apenas algumas fotos e uma frase de efeito tornavam a pessoa atraente, na rede social de Mark Zuckerberg a proliferação de fotografias e os posts escritos pareciam querer avisar que havia algum engano naquele match. Dois ambientes; duas pessoas.

Conheci minha namorada no Tinder. Gostei das fotos dela. Conversamos pouco, quase nada, e marcamos de nos encontrar em um café, no início da noite. Quando cheguei, ela já estava lá. Andei em direção à mesa preocupado em manter o corpo ereto, com passos firmes, tentando transmitir uma segurança que não sentia. Assim que me aproximei, chamei-a pelo nome, me esforçando para a voz rouca sair serena e ligeiramente atraente.

6

CENA 1 - SALA DE AULA, INTERIOR, NOITE.

Comunicação e...

- Boa noite. Eu serei o professor de vocês na disciplina de Teoria da

Ouve-se um cochicho entre os alunos até que um deles, em tom zombeteiro, me interpela:

- Você é o professor mesmo? Isso é aula-trote, né?

\section{CENA 2 - SALA DE AULA, INTERIOR, NOITE.}

Entro na sala de aula, sento sobre a mesa de professor, as pernas balançam levemente. Os alunos vão entrando aos poucos, sozinhos ou em pequenos grupos. Anoto meu nome no quadro e o meu e-mail.

- Boa noite.

- Boa noite.

- Meu nome é Tiago, serei o professor de vocês de Técnicas de Redação Jornalística neste período. 
Um aluno levanta a mão.

- Alguma dúvida?

- Você não é muito novo pra ser professor, não?

\section{CENA 3 - SALA DE AULA, INTERIOR, NOITE.}

Chamo um aluno por vez à minha mesa. Entrego a prova. Comento as respostas, explico os erros, abro espaço para argumentação. Gosto desse processo. Acho pedagógico. A turma é grande. A prática toma quase metade do tempo da aula. Vejo um aluno de uma outra turma entrar e sentar ao fundo. Ele fica conversando com outros estudantes, ri, faz gestos. Ele não é meu aluno, está lá para se divertir com os colegas. Quando termino de entregar as provas, faço um sinal amistoso com a mão, solicitando que ele saia de sala, porque a aula iria começar.

- É comigo?

- Isso. Pode sair de sala, por favor? Vou começar a aula agora.

- Pode dar a sua aula, não vou atrapalhar, não.

(Ele não me parece disposto a sair de sala. Está lá só para conversar. É importante que ele saia para não atrapalhar ainda mais a aula. Essa turma é enorme, mais de 60 alunos, e a conversa é generalizada. Vou manter a amabilidade, quem sabe em tom amistoso ele perceba que deve se retirar).

- É, mas você não é aluno dessa turma, dá licença para eu iniciar a aula, por favor.

- Sério? Você está mesmo me expulsando de sala?

Ele aumenta o tom de voz, ri enquanto fala, ironicamente, olha para os lados buscando a cumplicidade de seus colegas, anos de conflitos entre professores e alunos voltam à tona.

(Tenho que terminar com essa discussão rapidamente, não posso entrar na dele, tenho que me impor. Não vou dar margem para argumentações. É preciso ser firme e não perder a razão).

- Por favor, poderia se retirar de sala. Tenho que começar a minha aula.

Ele levanta, abre os braços, ri, balança a cabeça negativamente. A turma está quieta, olha com apreensão. Ele debocha, me enfrenta.

- Isso não pode ser sério, você está mesmo me expulsando de sala? É isso?

(A situação piora. Ele faz um show. Parece gostar de enfrentar o professor. Quer plateia. Estou nervoso. Ele tem que sair de sala agora. É uma questão de manter o pulso sobre a turma. Não posso mais recuar. Ele é maior do que eu. Se fosse na rua, não o responderia com medo de apanhar. Mas estou em sala de aula. Sou o professor e ele, o aluno. Nós, professor e alunos, reconhecemos esse ambiente e suas regras. Existe uma hierarquia. A que ele está enfrentando. Ele não vai me bater em sala de aula. Preciso ser firme).

- Não vou discutir. Sai de sala!

(Será mesmo que não vai sair? O que farei agora se ele continuar resistindo à minha ordem? Ele não para de gesticular. É um ator. Está interpretando somente para os colegas? Ou também quer ficar bonito no enquadramento das câmeras de segurança 
instaladas na sala de aula? Estamos num reality show? A hipótese é assustadora, mas parece tão provável. É só encenação ou é mesmo verdade? Me sinto como o Truman...). - Não vou sair, eu pago o seu salário.

\begin{abstract}
Muitos romances em primeira pessoa podem "fingir" o relato verídico de uma experiência pessoal, sem que o leitor seja capaz de desfazer a ambiguidade entre a história concreta de um $e u$ real, que remeteria ao autor, e a sua recriação metafórica em termos de invenção ficcional (Wander Melo Miranda).
\end{abstract}

Lancei um livro recentemente, o meu segundo de ficção. É um livro de contos. A última história dá nome à obra, Petaluma. Um texto autobiográfico. O narradorpersonagem tem o meu nome. Escrevi em fragmentos, como faço agora com este artigo, não por acaso (ergo uma fachada pessoal), também memorialístico. O primeiro parágrafo dá o tom autorreflexivo e põe a experiência pela qual passei em perspectiva: "Hoje, nove ou dez anos depois, vejo Petaluma como a reunião das minhas neuroses. Não percebia naquele período. Não percebi durante esse tempo todo. Agora enxergo. Estou mais claro. Concreto. Não mais um fantasma. Aquele ser que passou por Petaluma."

Tenho sérias dúvidas em relação ao gênero do texto, não sei se é autobiografia ou/e conto ou/e memória ou/e novela ou/e autoficção ou/e...

outras variantes do espaço biográfico podem produzir um efeito altamente desestabilizador, talvez como "desforra" diante de um excesso de referencialidade 'testemunhal': as que, sem renúncia à identificação de autor, se propõem jogar outro jogo, o de transtornar, dissolver a própria ideia de autobiografia, diluir seus umbrais, apostar no equívoco, na confusão identitária ou indicial - um autor que dá seu nome ao personagem ou se narra na segunda ou terceira pessoa, faz um relato fictício com dados verdadeiros ou o inverso, inventa para si uma história-outra, escreve com outros nomes etc. etc. (Leonor Arfuch)

Tentar definir o gênero parece não fazer sentido.

8

$\mathrm{Eu}$, como professor, oriento alunos de graduação em suas monografias de conclusão do curso. Eu, como aluno de doutorado, sou orientado em minha pesquisa. As reuniões de orientação costumam ter sempre a mesma característica:

\title{
Eu, orientador
}

- Então, li o seu projeto, mas gostaria que me falasse um pouco dele antes de fazer meus comentários.

A orientanda faz uma cara de desespero. Fica quieta alguns segundos certamente, parecem minutos para ela. Balbucia palavras genéricas, gagueja. Ela tenta disfarçar a tremedeira do corpo. Eu permaneço quieto, aguardando. Ela avança na explicação do projeto. Está confusa. Eu já esperava. É sempre assim. Não há problema. 
Após a breve exposição do que pretende fazer, eu começo a fazer algumas críticas construtivas, apontar alguns problemas do projeto, levantar questões para ela pensar. Ela concorda com tudo. Não sei se compreende o que falo, mas sempre assente com a cabeça. Às vezes sorri, nervosa. Ao fim, indico uma pequena bibliografia para iniciarmos o trabalho. Ela agradece e vai embora.

\section{Eu, orientando}

- Então, li o seu projeto, mas gostaria que me falasse um pouco dele antes de fazer meus comentários.

Faço uma cara de desespero. Fico quieto alguns segundos - parecem minutos para mim. Balbucio palavras genéricas, gaguejo. Tento disfarçar a tremedeira que se instala em meu corpo. Minha orientadora permanece quieta, aguardando. Avanço na explicação do projeto. Estou confuso. Ela já devia esperar. Deve ser sempre assim. Não parece haver problema. Após a breve exposição do que pretendo, ela começa a fazer algumas críticas construtivas, apontar alguns problemas, levantar questões para eu pensar. Concordo com tudo. Acho que ela sabe que não compreendo o que fala na totalidade, mas sempre confirmo com a cabeça. Às vezes sorrio, nervoso. Ao fim, ela indica uma pequena bibliografia para iniciarmos o trabalho. Agradeço e vou embora.

9

Minha namorada faz mestrado em filosofia da arte. Não entendo muito quando fala da pesquisa, mas adoro ouvi-la, é muito estimulante intelectualmente. Fora que é uma baita artista. Ela não tem bolsa no mestrado. Para pagar as contas, tem um emprego de meio expediente como atendente de telemarketing.

Outro dia, liguei cedo para o celular dela, antes de ela sair para a aula. O telefone tocou um bocado até atender:

- Bom dia, em quê posso estar te ajudando?

Estranho. Tudo, a frase, a voz anasalada...

- Quê?

- Senhor, bom dia, como posso estar te ajudando?

- Meu amor, sou eu. Isso é jeito de atender o telefone?

Ela ficou em silêncio do outro lado da linha. Depois, deu risadas.

- Desculpe, meu lindinho, estava dormindo, acordei no susto com o celular, devia estar sonhando com o trabalho. Atendi como se estivesse lá.

OK, justificava em parte, mas o gerundismo, a voz anasalada...

- Mas por que esse gerúndio, esse sotaque estranho?

- Ah, nunca te contei?

- Não sei, não lembro muito bem das coisas, você sabe. Conta aí.

- Uma vez um antigo supervisor disse que eu soava um pouco pedante ao telefone, que não era uma boa forma de falar com os clientes. Aí, me deu uma cartilha para ler, me passou umas frases prontas, pediu para eu repetir umas três vezes. E ainda disse que era para eu agradecer a dica, que se fosse um outro supervisor poderia ter me demitido, que eu estava tentando parecer mais qualificada do que o emprego pedia e que isso não era uma boa coisa... Mudei na hora, não posso perder esse trabalho agora. 
Me lembrei de quando fui procurar emprego em uma locadora, ainda com 18 anos. Na entrevista com a proprietária, ela me perguntou o meu gosto por filmes. Citei uns lançamentos brasileiros, alguns latino-americanos e uns clássicos franceses.

- Ah, você tem um gosto diferente para alguém da sua idade. Rapazes jovens como você costumam assistir a filmes de ação, terror, Rambo, MIB, Pânico...

- Não, mas eu gosto de tudo, assisti a esses filmes, não se preocupe.

Não fui chamado para o emprego. Naquela época, estudava economia. Tentei justificar a minha contratação dizendo que me adaptaria à demanda, que a minha contratação teria um ótimo custo-benefício e que eu certamente agregaria valor à loja. Se fosse hoje, talvez falasse de interação diádica com os clientes, defendesse uma leitura não hermenêutica de $M I B$ ou em como eu conseguiria me sair bem como atendente da locadora, porque estamos sempre atuando em nossas vidas. Acho que não seria chamado para o emprego da mesma forma.

10

22 de outubro de 2014

De: Tiago

Para: $\mathrm{H}$.

Oi, H., tudo bem?

O lançamento do meu livro, sobretudo a repercussão do conto "Conto", está me fazendo pensar em uma série de coisas e, de alguma forma, me parece que pode ser parte da pesquisa, por ser um texto autobiográfico.

Apesar de eu já ter dois livros lançados anteriormente, só agora estou começando a me aceitar como escritor. O lançamento desse livro e os feedbacks que venho recebendo - resenhas, críticas, comentários de amigos, e-mails... - estão, através do olhar do outro, operando uma modificação na minha autoimagem e, dessa forma, começo a me colocar e me apresentar como escritor ("sou escritor"). Parece-me claro que esse espaço biográfico em que estou trabalhando é um processo de construção e afirmação desse escritor em que venho me transformando.

Assim, do mesmo modo que "Conto" foi escrito como trabalho de conclusão da disciplina do J. D. (o que me mostrou, na prática, a incapacidade de a escrita ser a verdade, a impossibilidade de escrever a memória fielmente e de como qualquer tentativa de contar o que aconteceu seria apenas uma construção dentro da linguagem, com suas regras etc., além de ver como a memória/esquecimento é criadora e de como a narrativa fragmentária parece ser uma possibilidade interessantíssima de narrar o que aconteceu) gostaria de, agora, pensá-lo para as disciplinas da R. e da S., bem como para a da M..

Para a R./S., pretendo olhar "Conto" como essa narrativa da memória sobre o trauma/sofrimento. A bibliografia da disciplina é muito interessante para isso e, como estamos lendo muito Benjamin, a ideia de uma reflexão fragmentada e literária está muito presente. 
Para a M., a análise é em termos de performance do autor e do narrador, as estratégias de autofiguração no momento da escrita, os feedbacks que atravessam o autor empírico e fazem eu me apresentar de outra forma, a partir dessa interação entre o meu texto e o leitor e entre o leitor, após a leitura, e eu.

Bem, era isso. Queria compartilhar essas experiências, o que ando pensando, saber o que acha, sugestões...

Bjs, Tiago.

28 de outubro de 2014

De H.

Para: Tiago

Hallo, Tiago, desculpe a demora em responder.

Muito bom se sentir escritor, é o que você é mesmo. E a confiança em relação a uma escrita em primeira pessoa permite uma criatividade muito maior para uma "autobiografia".

Abs, $\mathrm{H}$.

11

Sou escritor profissional.

\section{Considerações finais}

Minto um pouco. Mas nem isso consigo deixar de revelar. Não sou bom com mentiras. Um falso mentiroso. Sou mesmo um performer.

\section{Referências bibliográficas}

ARFUCH, Leonor. O espaço biográfico: dilemas da subjetividade contemporânea. Rio de Janeiro: EdUERJ, 2010.

GOFFMAN, Erving. A representação do eu na vida cotidiana. $9^{a}$ ed., Petrópolis, Rio de Janeiro: Editora Vozes, 2001.

MIRANDA, Wander Melo. Corpos escritos: Graciliano Ramos e Silviano Santiago. São Paulo: Editora da Universidade de São Paulo; Belo Horizonte: Editora UFMG, 1992.

VELASCO, Tiago. Petaluma. Rio de Janeiro: Oito e Meio, 2014. 